\title{
District nurses meeting with and providing care to people with mental illness in health centers - An interview study
}

\author{
Sandra Pennbrant*1, Kristin Hansen ${ }^{2}$ \\ ${ }^{1}$ Division on Nursing, Department of Health Sciences, University West, Trollhättan, Sweden \\ ${ }^{2}$ NU Hospital Group, Västra Götaland Regional Council, Trollhätan, Sweden
}

Received: September 9, 2017

DOI: $10.5430 /$ cns.v5n4p96
Accepted: September 29, $2017 \quad$ Online Published: October 12, 2017

URL: https://doi.org/10.5430/cns.v5n4p96

\begin{abstract}
Objective: Primary healthcare is facing increasing numbers of people with mental illness. Although district nurses are expected to promote health and prevent illness, most health centers in Western Sweden have no psychiatric nurses. The aim of this study was to explore how district nurses experience meeting with and providing care to patients with mental illness in health centers.

Methods: Eight individual, semi-structured interviews with district nurses working in health centers were analyzed using qualitative content analysis.

Results: The district nurses felt that it is challenging to meet with patients with mental illness and that they need to learn to master such situations better. In particular, interaction challenge when assessing the patient's mental care needs, the dialogue challenge when attempting to achieve the patient's trust, and the competence challenge when trying to determine correct and safe care for the patient.

Conclusions: District nurses would benefit from having specific guidelines on how to provide person-centered care to patients with mental illness. Such guidelines would help district nurses in their planning and facilitating meetings with patients with mental illness and in their efforts to find solutions adapted to the specific patient, thus increasing both the district nurses' feelings of adequacy and the patient's feelings of safety and trust.
\end{abstract}

Key Words: District nurse, Health centers, Nursing, People with mental illness, Person-centered care, Qualitative content analysis

\section{INTRODUCTION}

Over the past decades, people with mental health problems have increased significantly. At present, one third of patients in Europe seeking primary healthcare assistance suffer from mental illness. ${ }^{[1,2]}$ There is a strong biological basis for many mental illnesses. Some mental illnesses can be caused by or exacerbated by high levels of stress. In Sweden, patients with mental illness are entitled to equal, knowledge-based and safe care. However, such care is not always provided, as the mental healthcare needs are often greater than the relevant care supply. Primary healthcare is particularly lacking in this respect. ${ }^{[3,4]}$ The issue of how knowledge about mental illness can have a positive effect, from the patient's perspective, on the meeting between a healthcare professional and a patient has been the focus of previous research. ${ }^{[5-9]}$ Nonetheless,

\footnotetext{
*Correspondence: Sandra Pennbrant; Email: sandra.pennbrant@hv.se; Address: Division on Nursing, Department of Health Sciences, University West, Gustava Melins Gata 2, SE-461 86, Trollhättan, Sweden.
} 
there is insufficient research on how district nurses experience their meeting with and care provision to patients with mental illness in health centers. The aim of this study was to explore this particular issue and to provide insights and conclusions that may be of benefit to both district nurses and their patients with mental illness.

\section{BACKGROUND}

In Sweden, district nurses are expected to provide health promotion and disease prevention. In their role, they meet with and support patients, as well as the patient's relatives, providing them with education, care and assistance. Among their tasks, district nurses take care of wounds, administer vaccines, assess skin disorders and allergies, perform blood pressure control, and provide information and education on diet, exercise, smoking and alcohol. In the course of their work district nurses collaborate with other healthcare professionals, such as physicians, physiotherapists and occupational therapists. ${ }^{[10]}$ In Sweden, there are no compulsory elements focusing on mental health training in district nurse education programs. ${ }^{[11]}$

\subsection{Previous research}

Studies show that patients with mental illness can be better supported by nurses specialized in psychiatric care than by general practitioners. ${ }^{[5,6]}$ Several studies show that nurses and district nurses in primary healthcare have insufficient skills as regards the assessment for mental illness and the development of appropriate treatment strategies. ${ }^{[12-14]}$ Wood $^{[15]}$ and Hapell and Cleary ${ }^{[16]}$ note that district nurses do not have specialized training in psychiatry. Blomberg and Hedelin $^{[17]}$ observe that mental illness is discovered earlier when there are psychiatric nurses in the primary healthcare team. Lee and Knight ${ }^{[18]}$ and Meehan and Robertsson ${ }^{[19]}$ conclude that district nurses have an important role in the prevention and management of mental illness. Galon and Graor, $^{[7]}$ Zolnierek $^{[8]}$ and Kauppi et al. ${ }^{[9]}$ all find that the attitudes and demeanor of health center nurses are important factors for patients with mental illness.

\subsection{Using a person-centered approach to inspire feelings of safety and trust}

To help patients with mental illness, district nurses should implement a person-centered approach and see the patient as a unique individual with specific needs. ${ }^{[20,21] ~ " I l l n e s s " ~ i s ~ t h e ~}$ patient's subjective experience of the condition and its symptoms and the "meaning" the patient assigns to this experience. Both the meaning and the patient's related behavior are determined by the type of illness, the patient's background and personality and by their cultural, economic and social environment. ${ }^{[22]}$ The person-centered care approach requires nurses to support and strengthen the individual patient by educating them about their own resources. A person-centered healthcare team works in partnership with patients in order to help them identify their abilities and develop the knowledge and confidence needed to make informed decisions about their own health care. ${ }^{[21]}$ For patients with a mental illness, the person-centered approach provides a greater feeling of well-being and coherence. ${ }^{[23]}$

The initial meeting is an important part of a person-centered approach and the interpersonal relationship and communication between district nurse and patient are central. District nurses take a holistic approach to nursing. ${ }^{[20]}$ Empathy and understanding are key elements in this holistic approach. Empathy is the ability to understand the patient's experiences and situation. Sympathy means being and feeling involved and connected with the patient, and wanting to alleviate the patient's suffering. The relationship between the district nurse and the patient is important because it affects the patient's ability to develop, implement and strengthen self-care. To develop mutual understanding, district nurses must have, in addition to nursing knowledge, a genuine interest to help and support the patient. ${ }^{[20]}$

Research describes how knowledge about mental illness can positively affect the meeting between the healthcare professional and the patient, especially in somatic healthcare. Such knowledge can also help identify barriers and facilitators in primary healthcare from a patient perspective. ${ }^{[5-9]}$ However, there are no specific descriptions of the meeting with and provision of care to patients with mental illness in health centers from a district nurse perspective.

\subsection{Aim}

The aim of the study was to explore how district nurses experience meeting with and providing care to patients with mental illness in health centers.

\section{MeTHODS}

To achieve this descriptive and exploratory study's aim, a qualitative approach, based on individual interviews, was chosen. This approach, which lets interviewees express themselves freely, enables researchers to understand and study the interviewee's subjective understanding and experiences. When a researcher wants to obtain as much information as possible within a specific domain, the qualitative descriptive and exploratory approach can be a powerful tool. ${ }^{[24]}$

\subsection{Participants and setting}

District nurses $(n=8)$ working at eight health centers in Southwestern Sweden participated in this study. The respondents had to be qualified district nurses with at least two 
years of experience as district nurses in health centers.

Health centers in Sweden provide outpatient healthcare for non-acute diseases and ailments, such as type 2 diabetes, chronic obstructive lung disease, cardiovascular disease, hypertension and chronic long-term diseases. The centers' healthcare professionals are mainly doctors, district nurses, assistant nurses and physiotherapists. ${ }^{[25]}$

Six operations managers were contacted by phone to request permission to carry out the study. Four of the managers accepted and were provided with written information and informed consent. The managers provided (by e-mail) names and phone numbers of district nurses who were willing to participate. The nurses were contacted by phone to explain the study's purpose and to agree on a time and venue for the interview. Before the interview, a detailed informational letter was sent to the nurses by e-mail. Eight district nurses, working at eight health centers, agreed to participate. Prior to each individual interview, written informed consent was obtained from the nurse.

All of the interviewed district nurses were women. Their ages ranged from 35 to 63 years. Their work experience at health centers ranged from 3 to 39 years. Of the eight health centers included in the study, five were privately operated and three were publicly operated. Five of the eight health centers were located in large towns; three were located in smaller towns.

\subsection{Data collection}

The data were collected during 2014. To ensure variation in the selection of interviewees, a strategic selection process was employed. This selection aimed to include health centers in both large and small towns in the region, as well as both privately and publicly operated centers. The purpose of strategic selection is to include people with different backgrounds, thus obtaining a more comprehensive picture of the subject. ${ }^{[24]}$

An interview guide was developed to maintain focus during the interviews. The interviews began by asking the district nurse to speak about her background: age, length of service as a district nurse, when she completed her district nurse training. Thereafter, questions were asked about her experience of meeting with and providing care to patients with mental illness. The same basic questions were asked during all of the interviews: "How do you experience meeting with patients with mental illness?" and "What should one keep in mind when meeting with patients with mental illness?" The interviews lasted for 30 to 45 minutes and were tape-recorded.

\subsection{Ethical considerations}

The study was approved by the Regional Academic Board of Ethics. Prior to the interviews, the district nurses signed consent forms and were informed that they could withdraw at will. Participant names were coded and interview tapes and transcripts stored securely to ensure confidentiality. The interviews were only used for this study.

\subsection{Data analysis}

Qualitative content analysis, as per Graneheim and Lundman, ${ }^{[26]}$ was used to analyze the district nurses' statements. The analysis focused on both the manifest and latent content in the text. Manifest analysis focuses on what the text "says"; this analysis focuses on the visible content that can be coded with little or no interpretation required. Latent analysis focuses on what the text "means"; this analysis requires interpretation of what the manifest content means.

The analysis began with verbatim transcription of the taperecorded interviews. The interviews were read several times to obtain an overall impression of the material. When reading the material, the question "What is being said?" was constantly asked to understand how the district nurses experienced meeting with and providing care to patients with mental illness. Words, phrases or sentences relating to the study's aim, so-called meaning units, were highlighted. To make the text more manageable, the meaning units were condensed, coded and grouped together according to their differences and similarities, while maintaining their core meaning. Subsequently, the latent content of the meaning units was deduced and the "How?" question was put to the material. Thus, subcategories were identified. The subcategories were compared and those with similar content were grouped into categories describing the statements' latent content. Finally, the underlying meaning, the latent content, of the categories was summarized in the form of a core theme. To ensure that the interpretation of the statements was as correct as possible, the analysis process was carried out iteratively. To confirm the validity of our interpretation of the district nurses' statements and the credibility of the results, quotations are provided in the results.

Twice during the analysis process, after analyzing interviews six and eight, the researchers assessed whether or not data saturation in relation to the study's aim had been achieved. At both occasions it was deemed that the material was rich in qualitative statements relating to the aim, that it was unlikely that additional interviews would add major patterns or variations to the statements obtained, that data saturation had been achieved and, consequently, that no further interviews were required. This confirmed Cooper and Endicott's ${ }^{[27]}$ conclusion that it is generally enough to interview five to eight 
persons to achieve data saturation.

\subsection{Rigor}

Credibility, dependability, confirmability and transferability are aspects contributing to a study's trustworthiness. One must consider all of these aspects when evaluating qualitative data. ${ }^{[28]}$ Credibility ${ }^{[29,30]}$ for this study was achieved by performing individual interviews with participants coming from different health centers and by letting them freely describe how they experience meeting with and providing care to patients with mental illness. The researchers continuously performed joint critical review throughout the analysis. The researchers read all of the interviews and jointly defined the categories and subcategories to ensure the study's dependability. Confirmability ${ }^{[29]}$ was achieved by constantly comparing codes and subthemes with the interview texts, and by relating the study's results to prior research. The context, selection and characteristics of the respondents have been provided to allow transferability. Descriptions of the methods for identifying and condensing meaning units have been given to enable readers to understand the background of the presented result. Interview texts are also presented so that readers may assess the transferability of the results to other settings. To strengthen the communicative credibility of the interview, respondent validation ${ }^{[30]}$ was achieved by means of dialogue with the district nurse during the interview. To avoid misunderstandings, summations were discussed during the interviews to offer the district nurse opportunities to make corrections or clarifications.

\section{Results}

Our analysis of the interviewed district nurses' statements revealed a core theme: "The challenge of mastering the situation." The district nurses experienced that meeting with and caring for patients with mental illness was often challenging, with three distinct challenges facing them: (1) an interaction challenge when assessing the patient's mental care needs, (2) a dialogue challenge when attempting to achieve the patient's trust, and (3) a competence challenge when trying to determine correct and safe care for the patient. These three challenges constitute the categories found in our analysis and comprise seven subcategories (see Table 1).

Table 1. Overview of the district nurses' experiences of meeting with and providing care to patients with mental illness in health centers

\begin{tabular}{|c|c|c|c|}
\hline Theme & \multicolumn{3}{|c|}{ The challenge of mastering the situation } \\
\hline Category & $\begin{array}{l}\text { Interaction challenge when assessing the } \\
\text { patient's mental care needs }\end{array}$ & $\begin{array}{l}\text { Dialogue challenge when attempting } \\
\text { to achieve the patient's trust }\end{array}$ & $\begin{array}{l}\text { Competence challenge when trying to determine } \\
\text { correct and safe care for the patient }\end{array}$ \\
\hline Sub-category & $\begin{array}{l}\text { - See the person behind the mental illness } \\
\text { - Establish a therapeutic relationship }\end{array}$ & $\begin{array}{l}\text { - Read between the lines } \\
\text { - Highlight the patient's positives }\end{array}$ & $\begin{array}{l}\text { - Feel inadequate and apprehensive } \\
\text { - Consult with experts } \\
\text { - Seek knowledge }\end{array}$ \\
\hline
\end{tabular}

\subsection{Interaction challenge when assessing the patient's mental care needs}

The district nurses stated that their ability to successfully interact with a patient with mental illness is crucial for identifying and assessing the patient's mental health care needs and influences how they experience the meeting. Interaction encompasses the district nurses' ability to see the person behind the mental illness and to establish a therapeutic relationship.

\subsubsection{See the person behind the mental illness}

To "see" the patient means having the ability to set aside time for the patient, to be on the same wavelength and show understanding. District nurses adjust their demeanor to the patient's mental illness condition and cognitive abilities.

"I treat everyone the same, but one must be on the same wavelength when talking to them [patients with mental illness], so that we understand each other, because they may also have cognitive problems" (District nurse 3 )

However, sometimes it is not possible to deal with patients with mental illness in the same way as other patients. With some patients with mental illness nurses must adapt their approach and demeanor to "feel" the situation.

"If the patient starts to cry, then one must take 20 minutes extra to make them feel cared for and seen" (District nurse 6)

"One adapts to each meeting depending on whom one is dealing with. There is a big difference between dealing with an asthma patient coming for a yearly check-up and a seriously mentally ill patient” (District nurse 2)

The district nurses stated that many patients with mental illness come in search of help with a somatic disorder, and that it is during the meeting that one discovers that they have mental illness problems. To be able to identify the patient's care needs and give the patient the opportunity to "open up" and speak freely about their problems during the meeting is a challenge.

"Most patients with mental illness do not come here for their 
mental illness but for something elsel.../The issue of their mental illness comes up during the talk/... I strive to convey the impression that I'm truly interested, not just curious, that I'm trying to talk to them/.../make the patient understand that I'm trying to help and that I truly care" (District nurse 1)

“It's important to make them feel safel... It isn't easy for them to just enter a room and open up to a stranger" (District nurse 6)

The district nurses noted that a patient can often show no signs of mental illness in the waiting room and then burst into tears once they enter the examination room. However, sometimes the patient's appearance, body language, posture and speech can indicate the presence of mental illness.

"Often, such patients use limited language/.../Their faces are often expressionless/... They can move in special ways/.../They are clearly in a down or sad mood/.../They can have dark rings around their eyes" (District nurse 1)

\subsubsection{Establish a therapeutic relationship}

The district nurses stated that it is a challenge to inspire feelings of safety and trust during meetings with patients with mental illness. If such safety and trust is achieved, it is easier for the patient to open up and talk about their situation, and for the district nurse to establish a therapeutic relationship and ask the questions necessary to assess the patient's care needs.

"One must be attentive and make them feel safe so that they dare talk openly/.. .IIf this succeeds, I feel that I have done good first work, upon which we can build" (District nurse 5)

The district nurses stated that meetings with patients with mental illness are generally more energy-consuming and require more planning than meetings with other patients. Nurses who meet with several patients with mental illness in a work day often experience more malaise and fatigue than normal, which can negatively affect both the nurse-patient interaction and the nurse's ability to assess the patient's care needs.

"I usually avoid booking more than one [patient with mental illness] per day. At most I can handle one in the morning and one in the afternoon" (District nurse 6)

Furthermore, the district nurses noted that their daily planning is often complicated by patients with mental illness coming to the health center without an appointment. Unscheduled visits by patients with mental illness can be stressful and often force nurses to reduce the time initially scheduled for other patients, which negatively impacts the quality of their care and the nurse's work situation.
“They [patients with mental illness] can feel very down and just come to us/... without an appointment when we are already fully booked/... They do not want to sit still in the waiting room and do not want to wait for their turn" (District nurse 2)

\subsection{Dialogue challenge when attempting to achieve the patient's trust}

According to the district nurses, it is important to achieve a good dialogue in order to get to know the patient, make the patient feel acknowledged and understood, and thus gain the patient's trust. In order to achieve good dialogue, district nurses must be capable of reading between the lines and of highlighting the patient's positives.

\subsubsection{Read between the lines}

The district nurses believed that to be able to assess the care needs of patients with mental illness nurses must be capable of "reading between the lines" when the patient is speaking about their everyday life. The district nurses stated that it is a challenge to be attentive when meeting and speaking with patients with mental illness. The district nurses believed that it is important to be able to handle the situation as constructively as possible and to "go after your heart".

"It may simply be a case of the patient needing someone to talk to" (District nurse 1)

"I must be attentive to the patient so that he or she feels safe and can open up to mel... Imake the patient feel'I can talk to her about it'\%.. If I succeed with this I feel I have done good work" (District nurse 5)

The district nurses noted that it is generally not possible to put direct questions to patients with mental illness. Instead, nurses try to obtain a picture of the patient's situation and state of mind by asking more exploratory and peripheral questions, which requires them to show great sensitivity to the patient's answers, demeanor and reactions.

"It's rare that one asks about it directly. First one tries to get a feeling. Then perhaps one can ask directly" (District nurse 2)

When patients with mental illness come to a district nurse for a somatic ailment the issue of their mental illness sometimes emerges towards the end of the meeting. On such occasions nurses generally feel dissatisfied or apprehensive about the situation and their ability to deal with it appropriately.

"Instead of talking about the patient's diabetes, we talk about their mental health, about how they cope with everyday lifel... IIt's sad to hear their stories and not be able to offer them more time/.../I do the best I can" (District nurse 5) 
"When I ask 'How are you?' I know that the reply may be long and complex/.../I cannot deal with it in 15 minutes/.../One avoids asking because one doesn't know what bomb may explode" (District nurse 3)

\subsubsection{Highlight the patient's positives}

The district nurses stated that it is a challenge to highlight positive aspects of patients with mental illness and their life situation, in particular when trying to focus on the patient's strengths and opportunities, because such patients generally focus on their own weaknesses.

"One should focus on what they are doing right/.. . They are very good at finding their own flaws/. . . You have two healthy children and a good job, and your employer lets you work at $50 \%$ because he wants to keep you on" (District nurse 6)

\subsection{Competence challenge when trying to determine cor- rect and safe care for the patient}

Having sufficient knowledge about mental illness is crucial for nurses' ability to meet with and provide care to patients with a mental illness. The district nurses expressed feelings of inadequacy in the context of trying to determine the correct and safe care for patients with mental illness. They feel they need support from mental health experts and more knowledge about mental illness.

\subsubsection{Feel inadequate and apprehensive}

The district nurses stated they often feel they lack the knowledge necessary to recognize and understand patients with a mental illness. The district nurses often rely on their own observations of the patient's body language, speech, eyes and overall behavior. District nurses need more medical knowledge about mental illness in order to be able to promote good meetings with patients with mental illness and to provide the best possible care.

“One feels inadequate. One doesn't know enough or what to say" (District nurse 4)

"One is grateful that one doesn't meet such people every day. It takes a lot to provide them with the right help/... It's difficult to know how to help them in the best way" (District nurse 2)

The district nurses stated that they do not know enough about mental illness to ask the right questions when they suspect or know that a patient suffers from a mental illness. They also do not know how to respond appropriately to the patient's statements or how to follow up on such patients. As the nurses feel they shoulder a great responsibility for detecting and assisting patients with mental illness, the nurses' lack of knowledge about mental illness places them in a difficult position.

Published by Sciedu Press
“I don't know how to proceed [with patients with mental illness] because I don't know what buttons I may be pressing/.. II listen and let them get it off their chest, but I don't know enough to offer good advice. I leave that to the experts" (District nurse 3)

The feeling of not knowing enough can make district nurses apprehensive about meeting patients with mental illness. Nurses sometimes hesitate to put questions to patients with mental illness for fear of triggering reactions they cannot handle. Nurses are more careful to plan what they say or do during meetings with patients with mental illness in order to not upset them.

"My impression is that some of my colleagues are afraid of meeting with them [patients with mental illness]" (District nurse 8)

\subsubsection{Consult with experts}

The district nurses noted that they often do not have enough knowledge to deal with a given patient with a mental illness. In such cases nurses listen carefully to the patient's story and try to set up an appointment with an appropriate counselor, physician or psychologist. District nurses also try to encourage patients with mental illness to make contact with other possible sources of assistance, such as family centers or occupational therapists.

“Traumatic events are complex/... If the patient's [mental illness] problems are major or long-lasting, it is better to pass them on to a specialist or counselor/. . ./I direct such patients to staff who are more knowledgeable in such matters" (District nurse 1)

"When I meet someone who is mentally ill, I pass them on to the right people" (District nurse 3 )

\subsubsection{Seek knowledge}

The district nurses stated that they constantly strive to gain more knowledge and understanding and to develop strategies for managing and helping patients with mental illness, in particular in the fields of self-harm or drug use. District nurses purposely use their meetings with patients with mental illness to try to increase their experience-based knowledge about such patients and how to handle and help them.

"There is always something to learn [when meeting a patient with mental illness], one can always improve oneself" (District nurse 6)

\section{Discussion}

The aim of this study was to explore how district nurses experience meeting with and providing care to patients with a mental illness in health centers. The results show that it is challenging, for district nurses to meet with and provide 
care to patients with mental illness in health centers in three distinct ways.

The study shows that the district nurses describe interaction as an important aspect. Interaction encompasses their ability to "see" the person behind the mental illness, to identify the patient's care and support needs, and to make the patient feel safe. An empathetic demeanor is important when encouraging patients to open up and speak about their life situation. To correctly assess a patient's mental health and tailor the care plan to the patient's needs, district nurses must be capable of reading between the lines in the patient's narrative. ${ }^{[20,31]}$ To have an empathetic demeanor and holistic view in the meeting with the patient can be related to the concept of person-centered care, in which the nurse places the patient's care needs in the center and strives to find and focus on elements in the patient's life. ${ }^{[21,22]}$

The district nurses in this study noted that the patient's body posture and movements may indicate depression or distress. District nurses who are capable of deducing the patient's feelings and mental health from their body language are more capable of providing good care and enhancing the patient's ability to perform their self-care. ${ }^{[20]}$ Eye contact between a district nurse and a patient is important for making the patient feel understood and respected. ${ }^{[7,32]}$ This helps the patient feel like a valuable and equal partner in the care, confirms the patient's experience of their illness, and promotes health on the basis of what health means for the patient. ${ }^{[33]}$

By starting with the patient's own story, the district nurses in the study believed that they could obtain a picture of the patient's life situation, motivations, resources and abilities, as well as the patient's emotional, social and practical needs, thus placing the patient's mental illness in a context. The trustful relationship requires seeing the patient as a whole and taking a person-centered approach. ${ }^{[20]}$ By adopting this approach district nurses may succeed in helping patients with mental illness feel safe as well as establish trust which is crucial for building a good nurse-patient relationship.

This study found that the district nurses feel that the ability to be a good interlocutor is important for exploring and assessing the patient's mental health, and for establishing a therapeutic relationship. Being a good interlocutor requires listening to, confirming and supporting the patient's statements, thus making them more willing to open up about their problems. By acknowledging the patient and being attentive to his/her words in the conversation, district nurses can inspire trust, thus promoting a good and successful meeting. Ekman et al. ${ }^{[21]}$ found that nurses who offer patients the opportunity to speak about their illness or discomfort can use the patient's story as a basis for developing nurse-patient collaboration that encourages and empowers the patient to actively partake in the search for and implementation of solutions to health care problems. Being a confirming and supportive interlocutor is a good strategy for getting to know patients with mental illness.

The district nurses in this study experienced that good care routines are important for their ability to plan the meetings with patients with mental illness, to set aside adequate time for such meetings, and to consult with experts when needed. Care routines that allow nurses to plan and dedicate time to the nurse-patient meeting, and to consult with other healthcare professionals when needed, are crucial for achieving good meetings with and care for patients with mental illness. According to the district nurses, it is preferable that such routines ensure that the patient meet with the same nurse(s), thus promoting the patient's feeling of continuity and safety in the care. Meetings with patients with mental illness are more energy- and time-consuming and require more planning. The district nurses in this study feel more malaise and fatigue than normal if they meet more than one patient with mental illness per day. According to Benner et al., ${ }^{[34]}$ district nurses need to be able to plan their meetings with patients with mental illnesses, to set aside the necessary time, and to meet with the patient in a calm and undisturbed environment, in order to promote a person-centered approach and to reduce the risk of nurse fatigue.

The district nurses in this study often feel inadequate when dealing with patients with a mental illness, and therefore appreciate having the opportunity to consult with or refer the patient to an appropriate counselor, physician or psychologist. Knowledge of mental illness is crucial for district nurses' ability to meet, deal with and provide care to patients with mental illness in an appropriate and optimal manner. Benner et al. ${ }^{[34]}$ noted that nurses gain clinical knowledge over time with experience and that knowledge thus gained allows them to become less dependent on rules and guidelines; patients can be understood on the basis of previous experience. When determining whether or not a patient suffers from mental illness, the district nurses in this study often rely on their own observations of the patient's body language, speech, eyes and overall behavior. The district nurses experienced the need for education about mental illness in order to be able to promote good meetings with and to provide the best possible care. According to Willman ${ }^{[35]}$ nurses' level of knowledge is important in their ability to provide evidenceand knowledge-based care. Evidence-based care means combining the patient's unique situation and wishes with the best possible science-based treatments. ${ }^{[35]}$

The district nurses in this study often do not feel sufficiently knowledgeable to meet with patients with mental illness and this feeling of inadequacy makes them apprehensive. They 
often experienced that they did not dare ask questions to patients with a mental illness for fear of not knowing how to deal with the patient's reaction and reply. The district nurses in this study want to do more for patients with a mental illness, but do not have the necessary tools to ask the right questions and do not know how to behave towards and follow up on such patients. District nurses need knowledge to understand and help patients with mental illnesses and build a safe and trustful relationship. ${ }^{[20]}$ Other healthcare professionals besides district nurses, using their specific perspectives and specialized knowledge, can contribute to the care and treatment of patients with mental illness. Collaboration between healthcare professionals is therefore needed to meet the often complex healthcare needs of patients with mental illness. ${ }^{[35]}$

\subsection{Practical implications}

The results of this study show that district nurses would benefit from better care routines and more knowledge about mental illness. District nurses can provide care to patients with mental illness using specific guidelines related to the person-centered care approach. Such guidelines can create conditions enabling district nurses to find and develop solutions that help them improve their planning and conduct meetings with patients with mental illnesses, thus increasing both the patient's and the nurse's feelings of safety and trust (see Table 2).

\subsection{Study limitations}

The study's trustworthiness may have been affected by the fact that the recruitment of district nurses was performed by health center directors. It can be argued that the small number of nurses included in this study reduces its transferability to other healthcare settings. However, the aim of qualitative content analysis is not to generalize, but to highlight individual experiences. The researchers ascertained that the interview material gathered ensured data saturation. Nevertheless, it would be valuable to include larger samples and more healthcare settings in future research on the issue of how district nurses experience meeting with and providing care to patients with mental illness.

Table 2. Guidelines for a person-centered care approach when meeting patients with mental illness

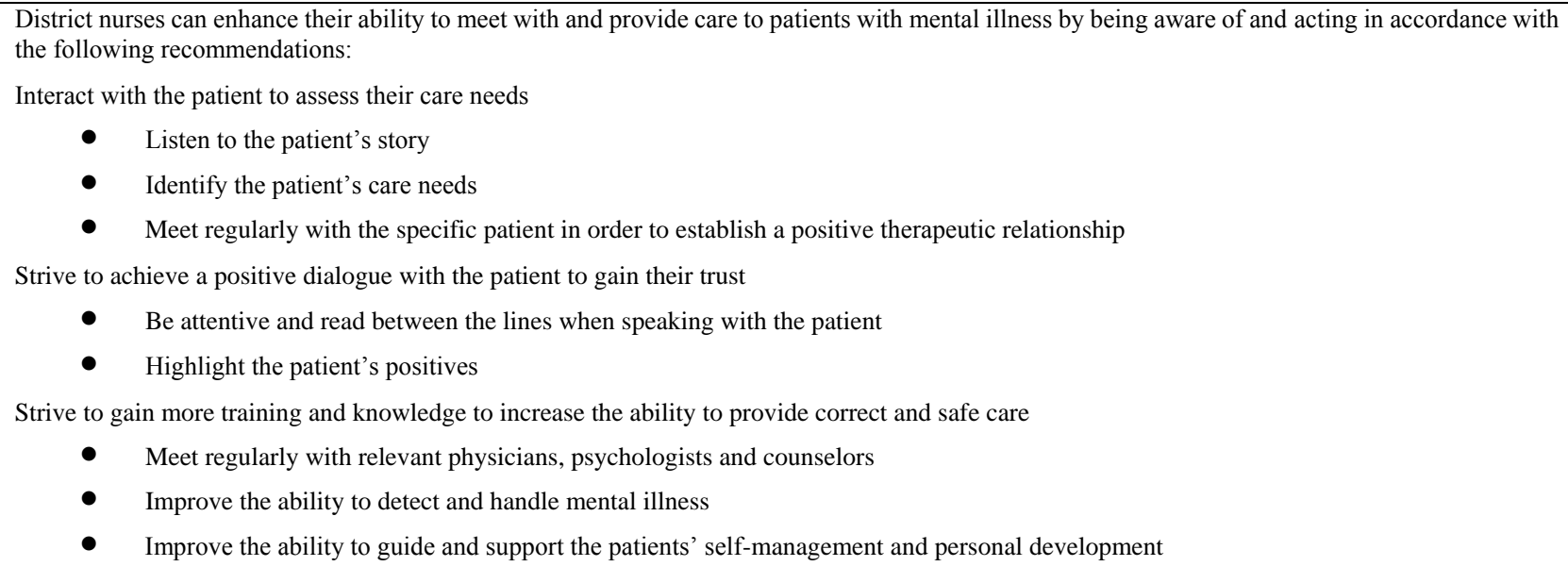

\section{Conclusions}

This study explored how district nurses experience meeting with and caring for patients with mental illnesses. The results show that district nurses feel they need more knowledge in order to assess for mental illness and to provide appropriate guidance and support. District nurses need time both to plan their meetings with patients with mental illness and to achieve a good dialogue and relationship with them, based on mutual trust and a sense of safety for the patient.

\section{ACKNOWLEDGEMENTS}

The authors thank Patrick Reis for his editing and proofreading assistance.

\section{CONFLicts OF INTEREST Disclosure}

The authors declare they have no conflicts of interest.

\section{REFERENCES}

[1] Wittchen HU, Jacob F. Size and Burden of Mental Disorders in Europe - A Critical Review and Appraisal of 27 studies. ECNP. 2005;

Published by Sciedu Press
15(4): 357-376. https://doi.org/10.1016/j.euroneuro. 20 05.04 .012

[2] Hilli Y, Wasshede K. Swedish school nurses' perspectives on caring 
for and promoting the health of adolescents with health problems A qualitative study. CNS. 2017; 5(4): 1-18. https ://doi.org/10 $.5430 / \mathrm{cns}$. v5n3p1

[3] Socialstyrelsen [Swedish National Board of Health and Welfare]. Psykisk ohälsa [Mental illness]. 2014 [cited August 27, 2017]. Available from: http://www. socialstyrelsen.se/psykiskoh alsa

[4] Socialstyrelsen [Swedish National Board of Health and Welfare]. Hälsan allt bättre - men ångest och oro ökar [Health is constantly improving - but anguish and anxiety is increasing]. 2017 [cited August 27, 2017]. Available from: http://www. socialstyrelsen. se/nyheter/2017

[5] Kendrick T, Simons L, Mynors-Wallis L, et al. A trial of problemsolving by community mental health nurses for anxiety, depression and life difficulties among general practice patients. The CPN-GP study. HTA. 2005; 9(37): 100-104. https ://doi .org/10.3310/ hta9370

[6] Kisely S, Campbell LA. Taking consultation-liaision psychiatry into primary care. IJPM. 2007; 37(4): 383-391.

[7] Galon P, Graor CH. Engagement in primary care treatment by persons with serve and persistent mental illness. Archives of Psychiatric Nursing. 2012; 26(4): 272-284. PMid: 22835747. https: //doi.org/10.1016/j.apnu.2011.12.001

[8] Zolnierek CD. Mental health policy and integrated care: global perspectives. J Psychiatr Ment Health Nurs. 2009; 15(7): 562-568. PMid: 18768008. https://doi.org/10.1111/j.1365-2850.2008.0 $1267 . \mathrm{x}$

[9] Kauppi K, Hätönen H, Adams CE, et al. Perceptions of treatment adherence among people with mental health problems and health care professionals. JAN. 2015; 71(4): 777-788. https ://doi .org/ $10.1111 /$ jan. 12567

[10] Distriktssköterskeföreningen [District Nursing Association]. Kompetensbeskrivning [Skills description]. 2008 [cited August 27, 2017] Available from: http://www.distriktsskoterska.se/

[11] Högskoleförordningen [Swedish Higher Education Ordinance]. Svensk författningssamling [Swedish Code of Statutes]. 2017; 844 [cited August 27, 2017]. Available from: https://www.uhr.se/studier-och-antagning/tillt rade-till-hogskolan/Hogskoleforordningen/

[12] Sharrock J, Happell B. Competence in providing mental health care: a grounded theory analysis of nurses' experiences. AJAN. 2006; 24(2): 9-15. PMid: 17285830.

[13] Shia N. The role of community nurses in the management of depression. Nurse Prescribing. 2009; 7(12): 548-554. https ://doi.org/ 10.12968/npre.2009.7.12.45631

[14] Medina CO, Kullgren G, Dahlblom K. A qualitative study on primary health care professionals' perceptions of mental health, suicidal problems and help-seeking among young people in Nicaragua. BMC Fam Pract. 2014; 2(15): 129. PMid: 24989871. https: //doi.org/10.1186/1471-2296-15-129

[15] Wood S. The contribution of nursing to public health practice in the prevention of depression. Nurs Health Sci. 2008; 10(3): 241247. PMid: 18786067. https://doi.org/10.1111/j.1442-2 $018.2008 .00401 . \mathrm{x}$

[16] Happell B, Cleary M. Promoting health and preventing illness: Promoting mental health in community nursing practice. Contemp Nurse. 2012; 41(1): 88-89. PMid: 22551278. https ://doi .org/10.108 0/10376178.2012.11002604

[17] Blomberg B, Hedelin B. Att få personlig vägledning - patienters erfarenheter av mötet med en psykiatrisjuksköterska inom primärvården. [Getting personal guidance - Patients' experiences of meeting a psychiatric nurse in primary health care]. Vård i Norden. 2007; 27(2): 25-29. https://doi.org/10.1177/010740830702700207
[18] Lee S, Knight D. District nurses' involvement in mental health: an exploratory survey. Br J Community Nurs. 2006; 14(4): 138-142. PMid: 16723902. https://doi.org/10.12968/bjcn.2006.11. 4.20832

[19] Meehan T, Robertson S. Clinical profile of people referred to mental health nurses under the Mental Health Nurse Incentive Program. Int J Ment Health Nurs. 2012; 22(5): 384-390. PMid: 23066840. https://doi.org/10.1111/j.1447-0349.2012.00885.x

[20] Travelbee J. Mellommeneskelige aspekter i sygepleje. [Interpersonal aspects of nursing]. Köpenhamn: Munkgarrd; 2006.

[21] Ekman I, Swedberg K, Taft C, et al. Person-centered care - Ready for prime time. Eur J Cardiovasc Nurs. 2011; 10: 248-251. PMid: 21764386. https://doi.org/10.1016/j.ejcnurse.2011.06 .008

[22] Helman CG. Culture, Health and Illness. (5 ${ }^{\text {th }}$ Ed.). London: Arnold; 2007.

[23] Arvidsdotter T, Marklund B, Taft C. Effects of an integrative treatment, therapeutic acupuncture and conventional treatment in alleviating psychological distress in primary care patients - A pragmatic randomized controlled trial. BMC Complement Altern Med. 2013; 13(1): 308. PMid: 24200100 . https://doi.org/10.1186/1472 $-6882-13-308$

[24] Polit DF, Beck CT. Nursing Research: Generating and Assessing Evidence for Nursing Practice. ( $9^{t h}$ Ed.). Philadelphia: Wolters Kluwer Health/Lippincott Williams \& Wilkins; 2012.

[25] Region Västra Götaland [West Gotaland Region]. Ansvarsfördelning och konsultationer mellan primärvård och specialistpsykiatri (vuxna). [Responsibilities and consultations between primary care and specialist psychiatry (adults)]. 2017 [cited August 27, 2017]. Available from: https://alfresco.vgregion.se/alfresco/service/ $\mathrm{vgr} /$ storage/node/content/8368/Ansvarsf $\%$ C3\%B6rdelni ng\%20och\%20konsultationer $\% 20$ prim $\%$ C $3 \%$ A4rv $\%$ C $3 \%$ A 5 rd $\% 2$ 0och\%20specialistpsykiatri.pdf $\mathrm{a}=\mathrm{fal}$ se\&guest $=$ true

[26] Graneheim UH, Lundman B. Qualitative content analysis in nursing research: concepts, procedures and measures to achieve trustworthiness. Nurse Educ Today. 2004; 24(2): 105-12. PMid: 14769454. https://doi.org/10.1016/j.nedt.2003.10.001

[27] Cooper S, Endacott R. Generic qualitative research: a design for qualitative research in emergency care? EMJ. 2007; 24(12): 816-9. https://doi.org/10.1136/emj . 2007.050641

[28] Lincoln YS, Guba E. Naturalistic Inquiry. Beverly Hills, CA: Sage; 1985.

[29] Morse JM. Critical Issues in Qualitative Research Methods. Thousand Oaks, CA: Sage Publications; 1994.

[30] Silverman D. Interpreting Qualitative Data Methods for Analyzing Talk, Text and Interaction. ( $3^{\text {rd }}$ ed.). London: Sage; 2000.

[31] Dahlberg K, Segesten K. Hälsa och vårdande: i teori och praxis. [Health and caring: in theory and practice]. Stockholm: Natur \& Kultur; 2013.

[32] Knapik GP, Heifner-Graor C. Engaging persons with severe persistent mental illness into primary care. JNP. 2013; 9(5): 283-287. https://doi.org/10.1016/j.nurpra.2013.02.019

[33] Dahlberg K, Segesten K, Nyström M, et al. Att förstå vårdvetenskap. [Understanding health sciences]. Lund: Studentlitteratur; 2003.

[34] Benner P, Tanner CA, Chelsea CA. Expertise in Nursing Practice: Caring, Clinical Judgment and Ethics. New York: Springer Publishing Company; 1996.

[35] Willman A. Kärnkompetensen evidensbaserad omvårdnad. [Core competency, evidence-based nursing]. In J. Leksell and M. Lepp (Ed.), Sjuksköterskans kärnkompetenser. [The nurse's core competencies]. Stockholm: Liber; 2013. 193-200 p. 